\title{
Photodynamic Therapy for Esophageal Cancer
}

\author{
Takahiro Inoue and Ryu Ishihara \\ Department of Gastrointestinal Oncology, Osaka International Cancer Institute, Osaka, Japan
}

Photodynamic therapy, a curative local treatment for esophageal squamous cell carcinoma, involves a photosensitizing drug (photosensitizer) with affinity for tumors and a photodynamic reaction triggered by laser light. Previously, photodynamic therapy was used to treat superficial esophageal squamous cell carcinoma judged to be difficult to undergo endoscopic resection. Recently, photodynamic therapy has mainly been performed for local failure after chemoradiotherapy. Although surgery is the most promising treatment for local failure after chemoradiotherapy, its morbidity and mortality rates are high. Endoscopic resection is feasible for local failure after chemoradiotherapy but requires advanced skills, and its indication is limited to within the submucosal layer by depth. Photodynamic therapy is less invasive than surgery and has a wider indication than endoscopic resection. Porfimer sodium (a first-generation photosensitizer) causes a high frequency of side effects related to photosensitivity and requires the long-term sun-shade period. Talaporfin (a second-generation photosensitizer) requires a much shorter sun-shade period than porfimer sodium. Photodynamic therapy will profoundly change treatment strategies for local failure after chemoradiotherapy. Clin Endosc 2021;54:494-498

Keywords: Endoscopic mucosal resection; Endoscopic submucosal dissection; Endoscopic treatment; Esophageal squamous cell carcinoma; Photodynamic therapy

\section{INTRODUCTION}

Esophageal cancer is the eighth most common cancer and the sixth highest cause of cancer-related death worldwide. ${ }^{1}$ It consists of two main histological subtypes: esophageal squamous cell carcinoma (ESCC) and esophageal adenocarcinoma. ESCC is the predominant histological type worldwide, accounting for $>90 \%$ of cases in Asia, including Japan, Korea, and China. ${ }^{2}$ Its treatment includes endoscopic resection (ER), surgery, chemotherapy, radiation therapy (RT), or combinations of these therapies. Photodynamic therapy (PDT) is a promising treatment for ESCC; however, despite this fact, it is

Received: March 12, 2020 Revised: April 9, 2020

Accepted: April 9, 2020

Correspondence: Ryu Ishihara

Department of Gastrointestinal Oncology, Osaka International Cancer Institute, 3-1-69 Otemae, Chuo-ku, Osaka 541-8567, Japan

Tel: +81-6-6945-1181, Fax: +81-6-6945-1900, E-mail: ryu1486@gmail.com ORCID: https://orcid.org/0000-0002-8796-718X

(c) This is an Open Access article distributed under the terms of the Creative Commons Attribution Non-Commercial License (http://creativecommons.org/ licenses/by-nc/3.0) which permits unrestricted non-commercial use, distribution, and reproduction in any medium, provided the original work is properly cited. not widely used worldwide. Here, we review the efficacy and recent advances of PDT for the treatment of ESCC.

\section{HOW PDT WORKS}

PDT is a local treatment involving a photosensitizing drug (photosensitizer) with an affinity for tumors and a photodynamic reaction triggered by laser light. Injected photosensitizers are selectively incorporated into tumor tissues. Irradiating the tumor with laser light leads to the chemical excitation of its molecules, and the excitation energy generates reactive oxygen species, especially singlet oxygen radicals, which cause cell death by necrosis or apoptosis. ${ }^{3}$ In addition, endothelial cells involved in tumor neovascularization are damaged, resulting in microembolization. ${ }^{4}$ For esophageal cancer, PDT is performed endoscopically.

\section{HISTORY OF PDT}

In 1978, Dougherty et al. ${ }^{5}$ reported the efficacy of PDT for 
skin cancer, and several clinical studies have since been performed. In Japan, PDT using porfimer sodium and excimer dye laser (P-PDT) was approved by the Ministry of Health and Welfare for early-stage lung, esophageal, gastric, and cervical cancers in 1994 and was adopted as a treatment covered by the medical insurance in 1996. In ESCC, PDT was reported to be a potentially curative and tolerable salvage treatment for local failure after chemoradiotherapy (CRT). ${ }^{6}$

Subsequently, a second-generation PDT using talaporfin sodium and a semiconductor laser (T-PDT) was developed and adopted as a treatment covered by the medical insurance for early-stage lung cancer in 2003. ${ }^{7}$ A multicenter phase II study of ESCC demonstrated the high response rate and safety of T-PDT for the local failure after CRT or RT. ${ }^{8}$

\section{TRANSITION OF THE ROLE OF PDT FOR SUPERFICIAL ESCC}

In 1994, P-PDT, which showed a favorable complete response rate for superficial ESCC in a domestic clinical trial, ${ }^{9}$ was approved as a curative treatment in Japan. The indication criteria of P-PDT for superficial ESCC are as follows: (1) within $2 \times 2 \mathrm{~cm}$ in size, (2) smaller than half the circumference of the lumen, (3) mucosal or submucosal cancer, or (4) difficult to resect endoscopically. Two previous clinical studies reported the effectiveness of P-PDT for patients with superficial ESCC. Nakamura et al. ${ }^{10}$ reported that P-PDT achieved complete remission of 15 esophageal neoplastic lesions in seven patients. Lesions were relatively small (ranging from 5 to $30 \mathrm{~mm}$ in diameter). Histopathologically, among 15 lesions, 9 were squamous cell carcinomas and 6 were squamous dysplastic lesions. During follow-up (range, 4-51 months), no therapy-related complications and no recurrence of the initial lesion occurred in any patient. Tanaka et al. ${ }^{11}$ performed a long-term follow-up study and revealed that P-PDT was a potentially curative treatment for large superficial ESCCs that were too large to be resected endoscopically. In the study, 31 patients (82\%) had mucosal cancer, 7 (18\%) had submucosal cancer, and 33 (87\%) achieved complete remission. During a median follow-up period of 64 months (range, 7-125 months), the overall 5-year survival rate was $76 \%$ with no major complications or treatment-related mortality. In the era when ER was less widespread than it is today, P-PDT was often selected for superficial ESCC that are judged difficult for ER (e.g., bleeding tendency, fibrosis related to ER or RT).

However, with the increased use of ER, PDT for superficial ESCC has gradually declined. Recently, effective treatment options for superficial ESCC including endoscopic mucosal resection $^{12,13}$ and endoscopic submucosal dissection (ESD) ${ }^{14}$ have been developed and are now widely performed. ESD provides a high en bloc resection rate and accurate pathological diagnosis with lower recurrence rates. ${ }^{15}$ Lesions with an extensive circumference might develop esophageal stenosis after ESD and therefore are indicated for surgery or CRT. However, indications for ESD have been extended with the recent development of treatments for stenosis, including endoscopic balloon dilatation and local injection or oral administration of steroids. ${ }^{16}$ Based on these findings, ESD is considered for the treatment of patients with superficial esophageal neoplasia. Esophageal ESD was adopted as a treatment covered by the medical insurance in Japan in 2008 and is performed in general hospitals and advanced facilities. This use has led to the reduced role of PDT for superficial ESCC in Japan.

\section{PDT FOR LOCAL FAILURE AFTER CRT}

Local failure after CRT is a critical problem during the treatment for ESCC. CRT is a curative option for patients with unsuitable or refusal for surgery. Although CRT has a high complete response rate ( $87.5 \%$ for stage I, $62.2 \%$ for stage II/III), ${ }^{17.18}$ it also has a high locoregional failure rate $(50 \%-55 \%))^{19,20}$ Surgery is available as a salvage treatment for local recurrence after CRT. Although surgery can provide long-term survival, serious complications frequently occur, and the mortality rate is high (15\%). ${ }^{21}$ Accordingly, in the era when surgery was the only salvage therapy for local failure after CRT, the management of recurrent lesions was difficult and the development of curative and safe salvage treatment options was expected. Thus, PDT has once again attracted our attention.

If recurrence after CRT is discovered at an early stage (T1N0 or T2N0), then long-term survival could be expected with a salvage treatment. ${ }^{22}$ In addition, regional nodal failure within the field of elective lymph node irradiation was not common in patients achieving a complete response after $\mathrm{CRT} .^{23}$ Based on these studies, PDT as salvage therapy after CRT was reasonably considered as a important for local control at the primary site. A phase II clinical trial of salvage P-PDT after CRT demonstrated a favorable complete response rate (59.5\%) and overall survival rate at 3 years (38\%). ${ }^{6} \mathrm{PDT}$ is less invasive than surgery and is recognized as a curative and tolerable salvage treatment for patients with local failure after CRT without any metastasis. After the accumulation of cases in clinical practice, short- and long-term outcomes of P-PDT for patients with local failure after CRT were reported by Hatogai et al. ${ }^{24}$ In their study, the complete response rate of salvage P-PDT was 58.4\% (66/113), and approximately half of the cases (53.0\%: $35 / 66$ cases) maintained their complete response status (median follow-up time, 5.0 years). The progression-free survival and 
overall survival rates 5-year after the salvage PDT were 22.1\% and $35.9 \%$ after the median follow-up period of 61 months (range, 9-116 months). T1/2 before CRT, N0 before CRT, and the period between CRT and PDT ( $>6$ months) were associated with a better overall survival.

In recent years, ER has been used for local recurrence after $\mathrm{CRT} ;{ }^{25}$ however, it requires advanced skills and its indication is limited to within the submucosal layer by depth. PDT is indicated for lesions that invade the shallow muscle layer by depth or lesions where performing ER is technically difficult because of severe fibrosis associated with radiation.

\section{SECOND-GENERATION PDT USING TALAPORFIN SODIUM AND A SEMICONDUCTOR LASER}

Despite the effectiveness and minimal invasiveness of P-PDT, porfimer sodium causes a high frequency $(20.3 \%)$ of side effects related to photosensitivity (erythema, blisters, pigmentation) and requires long-term sun-shade period (4-6 weeks). ${ }^{26}$ However, talaporfin, a second-generation photosensitizer, requires a shorter sun-shade period than porfimer. The plasma half-life of talaporfin is $134 \mathrm{hr}$, which is shorter than that of porfimer sodium $(250 \mathrm{hr}),{ }^{27}$ and in a clinical trial for early lung cancer photosensitivity had disappeared in 28 of 33 patients (84.8\%) 2 weeks after the talaporfin administration. In a multicenter phase II study of T-PDT for ESCC, T-PDT had a good complete response rate (88.5\%) without skin phototoxicity. ${ }^{8}$ T-PDT was approved as a salvage treatment for patients with local failure after CRT without any metastasis in Japan. We report a case of local failure after CRT, for which T-PDT was remarkably effective and achieved complete response despite of esophageal stricture after the treatment (Fig. 1).

\section{ADVERSE EVENTS AND INDICATION CRITERIA OF PDT FOR PATIENTS WITH LOCAL FAILURE AFTER CRT}

Major adverse events related to PDT include esophageal stenosis, esophageal fistula including esophago-aortic fistula, and skin phototoxicity. In a clinical trial of P-PDT, 8 patients (32\%) developed photosensitivity, 6 (24\%) developed esophageal stenosis requiring balloon dilatation, and $4 \%(1 / 25)$

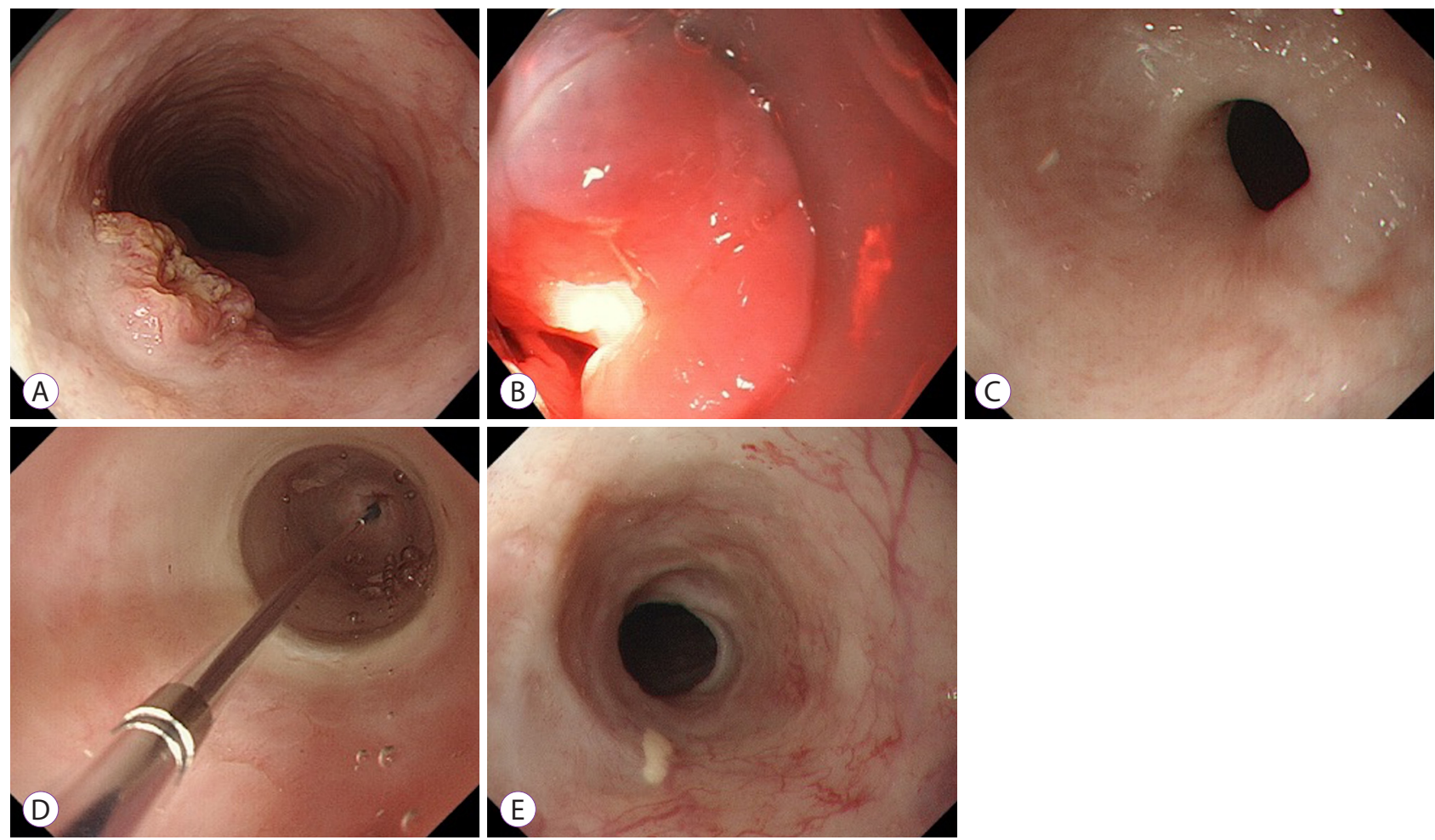

Fig. 1. A case of local failure after chemoradiotherapy (CRT) effectively treated with photodynamic therapy (PDT). (A) A local failure lesion after CRT limited to within T2. (B) PDT was performed. (C) Esophageal stricture occurred 3 months after PDT. (D) The stricture was treated with endoscopic balloon dilation. (E) A scar 18 months after PDT without evidence of recurrence. 
Table 1. Advantages and Disadvantages of Photodynamic Therapy for Esophageal Cancer

\begin{tabular}{lll}
\hline \multicolumn{2}{c}{ Advantages of PDT } & \multicolumn{1}{c}{ Disadvantages of PDT } \\
\hline PDT vs. Surgery & $\begin{array}{l}\text { Less invasiveness and better QOL and ADL } \\
\text { after treatment }\end{array}$ & $\begin{array}{l}\text { Less local curability } \\
\text { No indication for cancer invading into the outer muscular layer or deeper }\end{array}$ \\
& & $\begin{array}{l}\text { Impossibility to control metastases } \\
\text { Photosensitivity and sun-shade after PDT }\end{array}$ \\
PDT vs. ER & Curability for cancer invading into the deep & No indication for cancer in $>3$ or $>1 / 2 \mathrm{~cm}$ circumferential spread \\
& submucosa or inner muscular layer & $\begin{array}{l}\text { No specimen for histology } \\
\text { Photosensitivity and sun-shade after PDT }\end{array}$ \\
\end{tabular}

ADL, activity of daily living; ER, endoscopic resection; PDT, photodynamic therapy; QOL, quality of life.

of treatment-related deaths were related to esophago-aortic fistula. ${ }^{6}$ Regarding T-PDT, lessons learned from the clinical trial of P-PDT led to stricter indications and fewer adverse events. Esophageal stenosis was observed in 2 (7.7\%) patients only. No cases of photosensitivity, esophageal fistula, or treatment-related death occurred. ${ }^{8}$ Minamide et al. ${ }^{28}$ retrospectively compared T-PDT and P-PDT groups, consisting of 44 and 77 patients, respectively. Although significant differences were observed in the patient background, adverse events including skin phototoxicity, esophageal stricture, and esophageal fistula were all less frequent in the T-PDT group than those in the P-PDT group.

In Japan, following the T-PDT study, indications of PDT for local failure after CRT or RT are as follows: (1) lesions limited to within the shallow muscularis propria, (2) salvage ER not indicated due to incurability, (3) no invasion to the cervical esophagus, (4) longitudinal lesion length of $3 \mathrm{~cm}$ or shorter, and (5) circumference half or less of that of the lumen. ${ }^{8} \mathrm{PDT}$ is not recommended for lesions that potentially involve the aorta before CRT to prevent esophago-aortic fistula. Lesions of the cervical esophagus are also not candidates for PDT because the scope cannot be manipulated stably.

\section{PDT FOR ESCC IN THE FUTURE}

After the approval of talaporfin, the complexity of perioperative management and the adverse event rate of PDT decreased. Recently, T-PDT has gradually been recognized as a salvage option after CRT. Among laser treatments using endoscopes, PDT selectively kills tumor tissues instead of burning the surrounding normal tissues, and therefore, it can be a safe treatment if performed properly. Although the longterm outcome of T-PDT, a relatively new treatment, remains unclear and more clinical studies are needed, it is curative and has advantages, i.e., minimal invasiveness.
Surgery was regarded as the most promising treatment for local failure after CRT. However, considering its association with high morbidity and mortality rates together with recent favorable reports of PDT, treatment strategies for local failure after CRT require profound changes.

\section{CONCLUSIONS}

PDT for esophageal cancer is tolerable and effective especially for local failure after CRT. Its advantages and disadvantages are summarized (Table 1). It is also less invasive than surgery and has a wider indication than ER. Therefore, it is expected to be widely used in the future.

Conflicts of Interest

The authors have no potential conflicts of interest.

Author Contributions

Conceptualization: Takahiro Inoue, Ryu Ishihara

Data curation: TI, RI

Investigation: RI

Methodology: RI

Project administration: RI

Resources: RI

Supervision: RI

Validation: RI

Visualization: TI

Writing-original draft: TI

Writing-review\&editing: RI

ORCID

Takahiro Inoue: $\quad$ https://orcid.org/0000-0001-5470-9718

Ryu Ishihara: $\quad$ https://orcid.org/0000-0002-8796-718X

\section{REFERENCES}

1. Ferlay J, Soerjomataram I, Dikshit R, et al. Cancer incidence and mortality worldwide: sources, methods and major patterns in GLOBOCAN 
2012. Int J Cancer 2015;136:E359-E386.

2. Torre LA, Bray F, Siegel RL, Ferlay J, Lortet-Tieulent J, Jemal A. Global cancer statistics, 2012. CA Cancer J Clin 2015;65:87-108.

3. Dougherty TJ, Gomer CJ, Henderson BW, et al. Photodynamic therapy. J Natl Cancer Inst 1998;90:889-905.

4. Fingar VH. Vascular effects of photodynamic therapy. J Clin Laser Med Surg 1996;14:323-328.

5. Dougherty TJ, Kaufman JE, Goldfarb A, Weishaupt KR, Boyle D, Mittleman A. Photoradiation therapy for the treatment of malignant tumors. Cancer Res 1978;38:2628-2635.

6. Yano T, Muto M, Minashi K, et al. Photodynamic therapy as salvage treatment for local failure after chemoradiotherapy in patients with esophageal squamous cell carcinoma: a phase II study. Int J Cancer 2012;131:1228-1234

7. Kato H, Furukawa K, Sato M, et al. Phase II clinical study of photodynamic therapy using mono-L-aspartyl chlorin e6 and diode laser for early superficial squamous cell carcinoma of the lung. Lung Cancer 2003;42:103-111.

8. Yano T, Kasai H, Horimatsu T, et al. A multicenter phase II study of salvage photodynamic therapy using talaporfin sodium (ME2906) and a diode laser (PNL6405EPG) for local failure after chemoradiotherapy or radiotherapy for esophageal cancer. Oncotarget 2017;8:22135-22144.

9. Yoshida K, Suzuki S, Mimura S, et al. [Photodynamic therapy for superficial esophageal cancer: a phase III study using PHE and excimer dye laser]. Gan To Kagaku Ryoho 1993;20:2063-2066.

10. Nakamura T, Fukui H, Shirakawa K, Fujii Y, Fujimori T, Terano A. Photodynamic therapy of superficial esophageal cancer with a transparent hood. Gastrointest Endosc 2004;60:120-124.

11. Tanaka T, Matono S, Nagano T, et al. Photodynamic therapy for large superficial squamous cell carcinoma of the esophagus. Gastrointest Endosc 2011;73:1-6.

12. Inoue H, Endo M. Endoscopic esophageal mucosal resection using a transparent tube. Surg Endosc 1990;4:198-201.

13. Inoue $\mathrm{H}$, Endo $\mathrm{M}$, Takeshita $\mathrm{K}$, et al. Endoscopic resection of early-stage esophageal cancer. Surg Endosc 1991;5:59-62.

14. Oyama T, Tomori A, Hotta K, et al. Endoscopic submucosal dissection of early esophageal cancer. Clin Gastroenterol Hepatol 2005;3(7 Suppl 1):S67-S70.

15. Ono S, Fujishiro M, Niimi K, et al. Long-term outcomes of endoscopic submucosal dissection for superficial esophageal squamous cell neoplasms. Gastrointest Endosc 2009;70:860-866.

16. Ishihara R, Arima M, Iizuka T, et al. Endoscopic submucosal dissection/ endoscopic mucosal resection guidelines for esophageal cancer. Dig Endosc 2020;32:452-493.

17. Kato H, Sato A, Fukuda H, et al. A phase II trial of chemoradiotherapy for stage I esophageal squamous cell carcinoma: Japan Clinical Oncology Group Study (JCOG9708). Jpn J Clin Oncol 2009;39:638-643.

18. Kato K, Muro K, Minashi K, et al. Phase II study of chemoradiotherapy with 5-fluorouracil and cisplatin for stage II-III esophageal squamous cell carcinoma: JCOG trial (JCOG 9906). Int J Radiat Oncol Biol Phys 2011;81:684-690.

19. Cooper JS, Guo MD, Herskovic A, et al. Chemoradiotherapy of locally advanced esophageal cancer: long-term follow-up of a prospective randomized trial (RTOG 85-01). Radiation Therapy Oncology Group. JAMA 1999;281:1623-1627.

20. Minsky BD, Pajak TF, Ginsberg RJ, et al. INT 0123 (Radiation therapy oncology group 94-05) phase III trial of combined-modality therapy for esophageal cancer: high-dose versus standard-dose radiation therapy. J Clin Oncol 2002;20:1167-1174.

21. Swisher SG, Wynn P, Putnam JB, et al. Salvage esophagectomy for recurrent tumors after definitive chemotherapy and radiotherapy. J Thorac Cardiovasc Surg 2002;123:175-183

22. Swisher SG, Deford L, Merriman KW, et al. Effect of operative volume on morbidity, mortality, and hospital use after esophagectomy for cancer. J Thorac Cardiovasc Surg 2000;119:1126-1132.

23. Onozawa M, Nihei K, Ishikura S, et al. Elective nodal irradiation (ENI) in definitive chemoradiotherapy (CRT) for squamous cell carcinoma of the thoracic esophagus. Radiother Oncol 2009;92:266-269.

24. Hatogai K, Yano T, Kojima T, et al. Salvage photodynamic therapy for local failure after chemoradiotherapy for esophageal squamous cell carcinoma. Gastrointest Endosc 2016;83:1130-1139.e3.

25. Yano T, Muto M, Hattori S, et al. Long-term results of salvage endoscopic mucosal resection in patients with local failure after definitive chemoradiotherapy for esophageal squamous cell carcinoma. Endoscopy 2008;40:717-721.

26. Kato H, Horai T, Furuse K, et al. Photodynamic therapy for cancers: a clinical trial of porfimer sodium in Japan. Jpn J Cancer Res 1993;84:12091214.

27. Kessel D. Pharmacokinetics of $\mathrm{N}$-aspartyl chlorin e6 in cancer patients. J Photochem Photobiol B 1997;39:81-83.

28. Minamide T, Yoda Y, Hori K, et al. Advantages of salvage photodynamic therapy using talaporfin sodium for local failure after chemoradiotherapy or radiotherapy for esophageal cancer. Surg Endosc 2020;34:899-906. 